\title{
Pledoaje za perifernu strukturu - središte i periferija u tumačenjima Božidara Gagre
}

Prelog, Petar

Source / Izvornik: Institucije povijesti umjetnosti : zbornik 4. kongresa hrvatskih povjesničara umjetnosti, 2019, 131 - 136

Conference paper / Rad u zborniku

Publication status / Verzija rada: Published version / Objavljena verzija rada (izdavačev PDF)

https://doi.org/10.31664/z4khpu.18

Permanent link / Trajna poveznica: https://urn.nsk.hr/urn:nbn:hr:254:820179

Rights / Prava: Attribution 4.0 International/Imenovanje 4.0 međunarodna

Download date / Datum preuzimanja: 2023-04-26

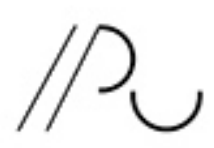

INSIIIUT ZA POVIJEST UMJETNOSI
Repository / Repozitorij:

PODEST - Institute of Art History Repository

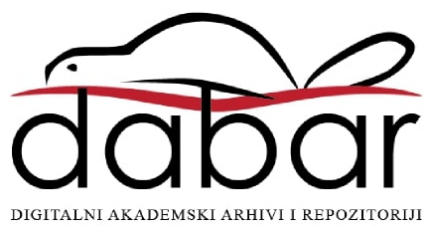




\section{Pledoaje za perifernu strukturu - središte i periferija u tumačenjima Božidara Gagre}

Nije pretjerano zaključiti da su različite razine odnosa središta i periferije zaokupljale povijest umjetnosti kao znanstvenu disciplinu veći dio dvadesetog stoljeća. Geografski pristup bio je svakako jedno od osnovnih polazišta, neizbježno u svim pokušajima identificiranja središta i periferije $u$ određenom umjetničkom razdoblju, a zatim i tumačenja njihovih umjetničkih tijekova te njihova međuodnosa. Latentno ili eksplicitno prisutna u mnogim metodološkim usmjerenjima filozofije, povijesti umjetnosti i kulture, geografska je dimenzija-od Herdera, Hegela, Schnaasea i Tainea primjerice, zatim Riegla, Dvořáka i drugih pripadnika Bečke škole povijesti umjetnosti, do Focillona, Kublera, Pevsnera i Białostockog-tako bitno određivala tumačenja pojedinih umjetničkih razdoblja, korpusa, oblikovnih i stilskih usmjerenja, ili pak pojedinačnih opusa i spomenika. ${ }^{1}$

Hrvatska je povijest umjetnosti, nastala na temeljima Bečke škole i pod utjecajem tradicije geografskih pristupa u njemačkoj povijesti umjetnosti, oduvijek podrazumijevala geografske postulate i u skladu s time posjedovala svijest o identitetskoj ulozi umjetničke produkcije. U tom se svjetlu može sagledati gotovo cjelokupno djelovanje nacionalne povijesti umjetnosti: od Izidora Kršnjavoga, Ljube Babića i Ljube Karamana, sve do mnogih suvremenih istraživača. Naime, činjenica geografskog položaja-koji je u povijesnoj, odnosno društvenoj, ekonomskoj i političkoj konstelaciji s pravom razumijevan kao rubni ili periferni-bila je prisutna u gotovo svim tumačenjima nacionalne umjetnosti različitih povijesnoumjetničkih razdoblja. Drugim riječima, uvijek je postojala svijest o poziciji nacionalnog umjetničkog prostora spram razvijenih kulturnih sredina i velikih umjetničkih središta, pa se u skladu s time pristupalo i valorizaciji. Tako se ne može poreći trajna aktualnost Karamanova određenja „domaće sredine”, odnosno njegova tumačenja pojmova graničnog, provincijalnog i periferijskog, ${ }^{2}$ kao svojevrsna polazišta za razmatranje općeg karaktera hrvatske

\section{Petar Prelog}

Institut za povijest umjetnosti, Zagreb pprelog@ipu.hr

https://orcid.org/oooo-oooI-76oI-938X
I Povijesni pregled geografskih ideja u filozofiji i povijesti umjetnosti, odnosno svojevrsnu kratku povijest geografije umjetnosti, vidi u: THOMAS DACOSTA KAUFMANN, Toward a Geography of Art, Chicago, The University of Chicago Press, 2004., I7-IO4.

2 Vidi: LJUBO KARAMAN, O djelovanju domaće sredine u umjetnosti hrvatskih krajeva, Zagreb, Društvo historičara umjetnosti N. R. H., I963. Drugo izdanje: LJUBO KARAMAN, Problemi periferijske umjetnosti. O djelovanju domaće sredine u umjetnosti hrvatskih krajeva, Zagreb, Društvo povjesničara umjetnosti Hrvatske, 20or. Karaman je tumačenje umjetničke periferije predstavio najprije kao kritiku Strzygowskog i njegove teze o „barbarskom” kontinuitetu predromaničke arhitekture u Dalmaciji. Bio je to prije svega istup protiv rasističkih i nacionalnih teorija u povijesti umjetnosti, ali također afirmacija geografske predodređenosti očitovane u „regionalnim” umjetničkim obilježjima. Karamanovo pobijanje Strzygowskog vidi u: LJUBO KARAMAN, Iz kolijevke hrvatske prošlosti, Zagreb, Matica hrvatska, I93o. 
umjetnosti, bez obzira na to usvaja li se temeljna Karamanova intencija ili joj se pak nastoji argumentirano suprotstaviti.

Središte i periferija bili su ključni pojmovi i u tumačenjima modernizma i avangarde, a posebice u pokušajima tkanja pripovijesti o umjetnostima kulturnih sredina koje su iz pozicije središta smatrana geografski rubnima, a u skladu s time i vrijednosno inferiornima. U ovome slučaju do izražaja dolazi sredinom dvadesetoga stoljeća uspostavljena „zapadna” perspektiva umjetničke historiografije koja ističe transnacionalnu kvalitetu modernizma i povijesnih avangardi, ali je razumijeva na ograničen način, ponajprije afirmirajući koncepte umjetničkog napretka i emisije „progresivnih” tendencija iz središta prema periferiji. Takva perspektiva-postajući dominantom pri uspostavljanju umjetničkih kanona toga razdoblja-privilegira u vrijednosnom, ali i svakom drugom smislu, umjetnost zapadnoga kulturnog kruga, a vrlo često izostavlja iz fokusa kao manje vrijedne srednjoeuropske i istočnoeuropske modernizme i avangarde, upravo one u kojima su lokalne posebnosti umjetničke produkcije više dolazile do izražaja. Iako su upravo te "rubne posebnosti”3 bile jamac transnacionalnosti kao osnovnog obilježja modernizma i avangarde, obrada kanoniziranih umjetničkih pojava i osobnosti nije ostavljala mnogo mjesta za drukčiju valorizaciju umjetničkih prinosa koji su nastajali izvan središta.

Tumačenje odnosa umjetničkih središta i umjetničke periferije pojavljuje se i u mnogim suvremenim metodološkim opredjeljenjima koja kritički pristupaju upravo tradicionalnim postulatima geografije umjetnosti. U tom smislu vrijedi spomenuti koncept „geohistorije umjetnosti” Thomasa DaCoste Kaufmanna, ${ }^{4}$ model „horizontalne povijesti umjetnosti” Piotra Piotrowskog, ${ }^{5}$ zatim postkolonijalnu teoriju u studijima vizualne kulture ${ }^{6}$ i, naposljetku, sve raširenije istraživačko polje „globalne povijesti umjetnosti". ${ }^{7}$ Svi navedeni pristupi, naime, propituju same temelje uvriježene geografske perspektive i pokušavaju pronaći drukčije ključeve valorizacije umjetničkih pojava ili korpusa u kontekstu globalizacijskih procesa, koji su pred povijest umjetnosti kao disciplinu postavili znatne izazove. Upravo je pitanje pronalaženja novih mogućnosti valorizacije hrvatske umjetnosti bilo u središtu znanstvenog interesa Božidara Gagre (I937.-2009.), povjesničara umjetnosti koji je djelovanjem umnogome obilježio prvu fazu sustavne znanstvene obrade hrvatske moderne umjetnosti $u$ šezdesetim i prvoj polovici sedamdesetih godina dvadesetog stoljeća. ${ }^{8}$ U njegovoj studiji Periferna struktura: od Karasa do Exata $^{9}$-nedvojbeno jednom od autorovih najvažnijih tekstova-pojam umjetničke periferije pojavljuje se kao središnji motiv, a valorizacija nacionalne moderne umjetnosti, kao umjetnosti periferije, nameće se kao gorući problem na koji povijest umjetnosti mora pokušati dati odgovore.

Periferna struktura objavljena je ı966. godine u prvome broju Života umjetnosti, „časopisa za pitanja likovne kulture” koji je pri Matici hrvatskoj pokrenuo upravo Gagro te čiji je glavni urednik bio do I97I. godine. Riječ je o časopisu koji je godinama, uz kataloge retrospektivnih i problemskih izložaba
3 „Rubnim posebnostima” označeni su avangardni prinosi nastali na bivšem jugoslavenskom prostoru kojima je bila posvećena izložba Avangardna umjetnost u regiji od I9I5. do I989. iz Kolekcije Marinko Sudac održana u Varaždinu 2005., Novome Sadu 2006. i Rijeci 2007. godine. Vidi: Rubne posebnosti. Avangardna umjetnost $u$ regiji od I9I5. do I989., katalog izložbe, (ur.) Marinko Sudac, Varaždin, Galerijski centar Varaždin, 2005.

4 Kritička sagledavanja ključnih koncepcija koje su uvjetovale geografski utemeljeno razmišljanje $\mathrm{u}$ povijesti umjetnosti vidi u zborniku: Time and Place. The Geohistory of Art, (ur.) Thomas DaCosta Kaufmann i Elizabeth Pilliod, Aldershot, Ashgate, 2005 .

5 Model „horizontalne povijesti umjetnosti” Piotrowski je razrađivao u više tekstova, među kojima se izdvajaju: PIOTR PIOTROwsKI, On the Spatial Turn, or Horizontal Art History, u: Umeni / Art, 5 (2008.), 378-383; PIOTR PIOTROWSKI, Towards a Horizontal History of the European Avant-Garde, u: Europa! Europa? The Avant-Garde, Modernism and the Fate of a Continent, (ur.) Sascha Bru et al., Berlin, De Gruyter, 2009, 49-58.; PIOTR PIOTROWSKI, How to Write a History of Central-East European Art?, u: Third Text, 96 (2009.), 5-I4. Tumačenje toga modela vidi u: LJILJANA KOLEŠNIK, Potreba revizije dominantne slike povijesti europske moderne umjetnosti i prijedlog „horizontalne povijesti umjetnosti” Piotra Piotrowskog, u: Zbornik 3. kongresa hrvatskih povjesničara umjetnosti, (ur.) Andrej Zmegač, Zagreb, Institut za povijest umjetnosti, 20I3., 30I-303.

6 Kritička razmatranja postkolonijalne teorije u kontekstu pristupa umjetnosti istočnoeuropske periferije vidi u: PIOTR PIOTROWSKI, East European Art Peripheries Facing Post-Colonial Theory, u: Nonsite.org, I2 (20I4.), 62-76, http://nonsite.org/article/ east-european-art-peripheries-facing-post-colonial-theory, pristupljeno: 8. II. 20I6. O postkolonijalnoj perspektivi tumačenja srednjoeuropske avangarde vidi: LIDIA GÆUCHOWSKA, The „New World" of the Avant-Garde and the „New States” in Central Europe. Pespectives on a Postnational and Postcolonial New Art History, u: Transnationality, Internationalism and Nationhood. European AvantGarde in the First Half of the Twentieth Century, (ur.) Hubert F. van den Berg i Lidia Głuchowska, Leuven, Peeters, 20I3., I83-2I2.

7 O važnosti postavljanja istraživačkoga fokusa na pitanja transkulturalnih susreta i razmjena, a usuprot tradicionalnim geografskim postulatima koji podrazumijevaju nacionalne granice te geografska i topografska određenja, vidi: Circulations in the Global History of Art, (ur.) Thomas DaCosta Kaufmann, Catherine Dossin i Béatrice Joyeux-Prunel, Franham, Ashgate, 20I5.

8 O povijesti znanstvene obrade hrvatskoga modernog slikarstva te ulozi Božidara Gagre vidi: IVANKA REBERSKI, Hrvatsko slikarstvo 20. stoljeća u svjetlu znanstvenih istraživanja, u:Zbornik I. kongresa hrvatskih povjesničara umjetnosti, (ur.) Milan Pelc, Zagreb, Institut za povijest umjetnosti, 2004., 247-253, 248.

9 BOŽIDAR GAGRO, Periferna struktura: od Karasa do Exata, u: Život umjetnosti, I (I966.), I5 $5^{-25}$. 
priređivanih u Modernoj galeriji i Umjetničkom paviljonu, bio gotovo jedino mjesto otvoreno za objavljivanje znanstvenih priloga o hrvatskoj modernoj umjetnosti. ${ }^{10}$ Osnovno pitanje na koje je nastojao odgovoriti temat prvoga broja novoga časopisa, naslovljen Sredina i umjetnost-a kako se navodi u nepotpisanom uvodnom tekstu temata-bilo je: „Djeluju li u našem ambijentu-viđenom u geografskom, historijskom ili sociološkom smislu-zakonitosti presudne za postojanje, razvoj i osobitosti naše umjetnosti?" I nadalje, a u vezi s problemima valorizacije: ,... da li za taj postojeći, faktički periferni kvantitet, vezan nedvojbeno uz dotični ambijent, važe bez priziva kriteriji centara, te je prema tomu put prema periferiji put apsolutnog degradiranja vrijednosti?"11 Razmatranje utjecaja „sredine”, odnosno „ambijenta”, na neku umjetničku produkciju nije, naravno, nov interpretacijski problem, već dio determinističke teorije koju je u devetnaestom stoljeću najsnažnije afirmirao francuski filozof, kritičar i povjesničar Hippolyte Taine i koja je u sklopu tradicionalnih geografskih nazora u povijesti umjetnosti posjedovala izniman utjecaj. ${ }^{12}$ Naposljetku, pojam „domaće sredine” i umjetničke periferije snažno je u hrvatskoj povijesti umjetnosti aktualizirao Ljubo Karaman ${ }^{13}$ nekoliko godina prije objave prvoga broja Života umjetnosti. Stoga se može zaključiti da su četiri teksta, objavljena u tematu Sredina $i$ umjetnost, svaki na svoj način, nastojala-potaknuta Karamanom-ponuditi odgovore na jedan od osnovnih problema interpretacije nacionalne umjetnosti. Milan Prelog je tako, kritički pristupajući temeljnim Karamanovim pojmovima provincije i periferije, $\mathrm{u}$ središte pozornosti postavio pitanja recepcije i stila ${ }^{14}$ Igor Zidić, polemizirajući s Taineovim postulatima te se referirajući i na poslijeratnu umjetničku produkciju, raspravlja o mogućnostima definiranja „našega prostora” u umjetnosti, ${ }^{15}$ dok Grgo Gamulin zahvaća u problematiku arhitekture i urbanizma u kontekstu afirmacije pojma regije. ${ }^{16}$ Božidar Gagro se pak u svojoj studiji bavi prije svega problemom valorizacije nacionalne moderne umjetnosti u stoljetnom vremenskom rasponu, od Vjekoslava Karasa, smatrana simboličnim početkom, do EXAT-a 5I, na koji se u tekstu samo neizravno referira kao na nedvojbeni novi početak. Autor, dakle, problemski zahvaća hrvatsku modernu umjetnost između tih dvaju početaka, kao oznaka u vremenu koje svojim obilježjima i vrijednostima omeđuju jedan umjetnički korpus.

Perifernu strukturu Gagro započinje Krležinom rečenicom iz negativnog osvrta na Grafičku izložbu šestorice mladih autora-Augustinčića, Grdana, Mujadžića, Pećnika, Postružnika i Tabakovića-održanu i926. u Salonu Ullrich. ${ }^{17}$ Taj je citat u svakom slučaju primjeren temi Gagrina teksta. Krleža, naime, ovdje daje neku vrstu definicije „naše civilizacije”: opisuje ju kao „periferičnu” sredinu koja ne pripada ni Balkanu ni Srednjoj Europi, pa joj stoga nikako ne pristaju ni preuzimanja, odnosno stilske posuđenice iz zapadnoeuropskih središta. Polazeći, dakle, od pojma periferije i postavljajući temeljno pitanje što je uistinu „naša”, ,hrvatska umjetnost”, ${ }^{18}$ Gagro ubrzo uvodi i problem valorizacije preko motiva „treće realnosti
Io O tome više u: PETAR PRELOG, Život umjetnosti-mjesto tumačenja hrvatskog modernizma / Život umjetnosti-Site for Interpreting Croatian Modernism, u:Život umjetnosti, 78-79 (2006.), I48-I53.

II Sredina i umjetnost, u: Život umjetnosti, I (I966.), 4.

I2 Ukratko o mjestu i važnosti Taineove determinističke teorije u kontekstu geografije umjetnosti vidi u: THOMAS DACOSTA KAUFMANN (bilj.I), 52-53.

I3 LJUBO KARAMAN (bilj. 2, I963.).

I4 MILAN PRELOG, Problem valorizacije u historiji umjetnosti naše zemlje, u:Život umjetnosti, I (I966.), 5-I4.

I5 IGOR ZIDIĆ, Naš prostor u umjetnosti, u:Život umjetnosti, I (I966.), 26-37.

I6 GRGO GAMULIN, Prostori u regijama, u: Život umjetnosti, I (I966.), $3^{8-53 .}$

I7 „Promatrajući grafičku izložbu ‘Šestorice' razmišljao sam o tajanstvenom gibanju ljepote, kako neodređena, infantilna, dekadentna ljepota zapadnjačkog urbanizma djeluje sablasno sugestivno u periferičnoj ni balkanskoj, ni centralnoevropskoj pseudocivilizaciji, kao što je, na primjer, naša civilizacija." MIROSLAV KRLEŽA, Grafička izložba 8. III.-20. III. I926., Obzor, II. ožujka I926., 2-3, 2. Dijelove toga teksta Krleža je inkorporirao u druge tekstove, među ostalim i u nekoliko kasnijih varijanti glasovitoga eseja Marginalije uz slike Petra Dobrovića. Gagro je tom prigodom-kako sam navodi-citiranu rečenicu preuzeo iz Marginalija, a ne izvornoga teksta. Gagro, I966., 23.

I8 BOžIDAR GAGRO (bilj. 9), I5. 
vanvremenskog imaginarnog muzeja” ${ }^{19} \mathrm{U}$ tom „zamišljenom carstvu" ujedinjuju se estetski vrijedna djela, ali istodobno vladaju i nepravde, jer-kako objašnjava autor-tamo „ima mjesta samo za ona najčišća, za vrhunska djela (...) a sve što je ispod (...) ostaje u mraku bezvrijednosti i u nedoumici mnogobrojnih kondicionala." ${ }^{20} \mathrm{Ta}$ činjenica, naravno, ima veze upravo s geografijom umjetnosti, pojmom periferije i presumpcijom manje vrijednosti umjetničke produkcije u periferijskoj sredini, pa tako i s pristupom tumačenju i valorizaciji nacionalne umjetnosti. Na to je pak izravno upozorio i Milan Prelog u istom broju Života umjetnosti. ${ }^{21}$ Gagro u vezi s time-na nešto drukčiji način od Preloga, koji se usredotočio ponajprije na problematiku recepcije-nudi promjenu valorizacijske paradigme, pa zapisuje: „... mjesto unaprijed problematičnog ispitivanja 'univerzalne vrijednosti' (što i nije drugo do mehanička primjena kriterija druge strukture, kriterija djela centralnih razvoja), valja nam poći od autentičnosti pojave, od njene logične ukotvljenosti u kulturnom prostoru u kojemu nastaje i u kojem je usvojena kao vrijednost po odredenom, bar privremeno relativnom kriteriju." ${ }^{22}$ Nadalje, tvrdi da je pri pokušaju određivanja vrijednosti hrvatske moderne umjetnosti i njezinih protagonista potrebno prihvatiti postojanje periferijskog fenomena i njegovu važnost te da je imperativ osloboditi se pretpostavke da je ta umjetnost morala bez zaostatka slijediti zapadnoeuropske uzore. ${ }^{23}$ Taj fenomen-zaključuje Gagro-,nije ni dobar ni loš, on je vrijednosti ravnodušan: on je strukturalni fenomen". ${ }^{24}$ Predlaže stoga estetski kriterij „koji se neće isključivati s komparativnim kriterijem, nego će se s njime nadopunjavati, služit će mu kao polazište i vrelo kritičke argumentacije". ${ }^{25}$

Unatoč nekim elementima rasprave koji nedvojbeno iskaču iz tipične modernističke paradigme, Gagrina pripadnost modernističkom univerzumu-koji podrazumijeva manje ili više linearno kretanje prema naprijed, odnosno kontinuirani umjetnički razvitak-može se prepoznati prije svega u prihvaćanju pojma „stilske retardacije”, kao važnoga određujućeg elementa „periferne strukture”. ${ }^{26}$ Iako tu retardaciju zove „takozvanom" te ističe da je ona "kvalitet periferne strukture", ${ }^{27} \mathrm{Ga}-$ gro se evidentno kreće u prostoru koji je određen prvenstveno pojmom stila-u slučaju periferije riječ je o njegovoj degradaciji, hibridnosti i retardaciji-ali i idejom o općem modernističkom napretku, što pojedinim umjetničkim fenomenima omogućuje pridavanje etikete „naprednih”. 28

Osim na opću analizu ključnih problema koje donosi periferna struktura-poput odnosa prema središtu, retardacije i hibridnoga karaktera umjetničkog stila, razine informiranosti u doba modernizacije i načina recepcije stila i forme-Gagro se u ovome tekstu usredotočuje na pokušaj sažetoga razlaganja predloženoga valorizacijskog koncepta, koristeći kao primjer opuse nekolicine hrvatskih umjetnika. Najprije spominje Vjekoslava Karasa kao prijelomnu pojavu, čime potvrđuje tada četrdesetak godina staru tezu Ljube Babića o Karasu kao ishodištu nacionalne moderne umjetnosti. ${ }^{29}$ Kao osnovni argument za Karasovo visoko vrednovanje u povijesnoumjetničkoj razvojnoj perspektivi Gagro se koristi novumom njegova
I9 BOŽIDAR GAGRO (bilj. 9), I5

20 BOŽIDAR GAGRO (bilj. 9), I6.

2I „Proglašenje nekog područja ‘periferijom' ili 'provincijom' predstavljalo je ne samo implicitnu (de)valorizaciju umjetničkih ostvarenja koja su tu nastajala nego je izvršilo negativan utjecaj i na razvoj naučnog istraživanja ovog 'provincijskog' umjetničkog materijala." MILAN PRELOG (bilj. I4), 5 .

22 BOŽIDAR GAGRO (bilj. 9), I6.

23 BOŽIDAR GAGRO (bilj. 9), 22.

24 BOŽIDAR GAGRO (bilj. 9), I7.

25 BOŽIDAR GAGRO (bilj. 9), 23.

26 BOŽIDAR GAGRO (bilj. 9), I9.

27 BOŽIDAR GAGRO (bilj. 9), I9.

28 Nije slučajno da se i Igor Zidić u istome broju Života umjetnosti osvrće na pojam retardacije, s time da on eksplicitno tvrdi kako „stil umjetnika ne može biti retardiran” te nastavlja: „Retardacija (kao i naprednost) pojam je koji se vezuje uz prosjek, uz proizvodnju, onaj nespecifičan i bezličan talog umjetničke aktivnosti." IGOR ZIDIĆ (bilj. I5), 37.

29 Više o obilježjima Babićeve valorizacije Karasova djela vidi u: IVANA MANCE, Uz Babićevu valorizaciju djela Vjekoslava Karasa, u: Zbornik radova znanstvenog simpozija Doprinos Ljube Babića hrvatskoj umjetnosti i kulturi, (ur.) Libuše Jirsak i Petar Prelog, Zagreb, Društvo povjesničara umjetnosti Hrvatske i Moderna galerija, 20I3., II6-II9. 
društvenog položaja te tvrdi da je upravo ta činjenica-a ne uska formalna analiza njegova djela-presudna za zaključak o „izuzetnosti” i „modernosti” toga umjetnika. ${ }^{30}$ Opus Marina Tartaglie-koji se nakon povratka u domovinu priklanja tradicionalnijim slikarskim vrijednostima- primjer je pak „degradiranja stilskoga kapitala" stečena u inozemstvu, ali uz važnu napomenu da to ne znači istodobno degradiranje opće vrijednosti umjetnikova izraza. ${ }^{31}$ Nadalje, Kraljevićev je sezanizam za Gagru iskustvo koje je „u našem ambijentu svježije i perspektivnije od do tog časa postojećih"32 i koje je mnogim umjetnicima omogućilo zaposjedanje novih, dotad neistraženih slikarskih područja, dok Josip Račić „bilježi uzlazan luk koji je po intenzitetu svojega otklona usporediv s odgovarajućim prikazom situacije bilo kojega velikog umjetnika na početku stoljeća." ${ }^{33}$ Naposljetku, na primjeru Ivana Meštrovića, Gagro zorno predočava za kakvu se valorizacijsku paradigmu zalaže. Meštrovića, naime, ne treba promatrati u kontekstu Rodina i Maillola, odnosno kao pukoga primatelja formalnih utjecaja glasovitih kipara. Nužno je-žele li se istaknuti neosporne vrijednosti njegova djela-naglasiti ono što mu je „vlastito”, „ono što se rodilo preko i mimo eventualnog utjecaja". ${ }^{34}$ Razumljivo je da isto vrijedi i za cjelokupnu hrvatsku modernu umjetnost. U Perifernoj strukturi-gustoj, slojevitoj, na pojedinim mjestima pomalo teško prohodnoj studiji, koju je napisao kada mu je bilo tek dvadeset i devet godina-Božidar Gagro postavio je ozbiljne teorijske temelje za drukčije sagledavanje vrijednosti hrvatske moderne umjetnosti. Otvorio je, drugim riječima, nove prostore tumačenja. Neke je od tih prostora sâm pokušao zauzeti u tekstovima koji su slijedili, a posebice u raspravi o Udruženju umjetnika Zemlja u europskom kontekstu iz I97o. $^{35}$ te problemsko-preglednoj studiji Putevi modernosti u hrvatskom slikarstuu iz I972. ${ }^{36}$ Periferna struktura bila je pak prilično utjecajna, citirali su je mnogi, njezini su pojedini dijelovi postali općim mjestima, ali širenje teorijske osnove i eventualnu plodnu nadogradnju Gagrina valorizacijska paradigma nije doživjela. Naposljetku, ni sâm Gagro-uvijek zainteresiran za problemski pristup, kontekstualizaciju i širok, gotovo panoramski pogled na korpuse, ali i pojedine opuse-nije detaljnije nastavio razrađivati ponuđeni koncept. Stoga je Periferna struktura tekst koji je po usredotočenosti na ključne probleme tumačenja i ambicioznom zahvatu u mogućnosti valorizacije umjetnosti periferije gotovo bez premca u povijesti pisanja o hrvatskoj modernoj umjetnosti. Osim toga, potrebno je zapaziti da su Gagrina razmišljanja danas, pola stoljeća poslije, opet osobito aktualna i poticajna. Suvremena perspektiva, naime, omogućuje da se Gagrine osnovne teze promatraju u kontekstu novih metodoloških usmjerenja, odnosno da se sagledaju izvan modernističkog okvira u kojemu su nastale. Usporedimo li ih s recentnim kritičkim čitanjima tradicionalne geografije umjetnosti-kojima su u središtu interesa ne samo tumačenja prostorne dimenzije umjetnosti nego i pitanja valorizacije prema novim kriterijima-može se zaključiti da su mnogi dijelovi Gagrina koncepta, unatoč njegovoj nedvojbenoj modernističkoj utemeljenosti, u zanimljivu
30 „Dok su drugi oko njega i dugo nakon njega građani koji slikaju, Karas predstavlja umjetnika, nov sociološki kvalitet, oduhovljenu savjest društva, i baš onog hrvatskog društva koje tek nazire svoju razvojnu perspektivu." BOŽIDAR GAGRO (bilj. 9), ı8.

3I BOŽIDAR GAGRO (bilj. 9), I8-ig.

32 BOŽIDAR GAGRO (bilj. 9), I9.

33 BOŽIDAR GAGRO (bilj. 9), 25.

34 BOŽIDAR GAGRO (bilj. 9), 25

35 BOŽIDAR GAGRO, Zemlja naspram evropske umjetnosti između dva rata, u: Život umjetnosti, II-I2 (I970.), 25-32.

36 BOŽIDAR GAGRo, Putevi modernosti u hrvatskom slikarstvu, u: Jugoslavenska umetnost XX. veka. I900-I920: Počeci jugoslovenskog modernog slikarstva, katalog izložbe, (ur.) Miodrag B. Protić, Beograd, Muzej savremene umetnosti, I972., 34-45. 
suglasju s pojedinim suvremenim metodološkim postav37 BOŽIDAR GAGRO (bilj. 9), I7. kama. Zbog svega navedenoga tu važnu Gagrinu studiju treba smatrati svojevrsnim pledoajeom za perifernu strukturu u kojoj se vrijednosti ne određuju prema kriterijima središta, odnosno odlučnim zagovorom za umjetnost periferije u kojoj geografska predodređenost nije grijeh, a retardacija-stilska, oblikovna ili konceptualna - postaje neospornom kvalitetom. Periferijski je fenomen-ponovimo na kraju Gagrinu ključnu misao-,jedinstven i dijalektičan”, „on nije ni dobar ni loš, on je vrijednosti ravnodušan". ${ }^{37}$

\section{(c) (i)}

Pledoaje za perifernu strukturu - središte i periferija u tumačenjima Božidara

Gagre/Petar Prelog/CC BY / 4.0

DOI: https://doi.org/Io.31664/z4khpu.I8 